\title{
Virtual Patients in Psychiatry: A Study of Mania And Schizophrenia.
}

\author{
Radhakanth C.* \\ "Professor Of Psychiatry, Maharajah's Institute Of Medical Sciences, Nellimarla, Vizianagaram, AP, India.
}

\begin{abstract}
This study using computer graphics based Virtual Patients of Mania and Schizophrenia is the first of its kind in Psychiatry in India. In Psychiatry, Virtual patients instead of live patients offer many advantages in cases of violence, suicide, complex phenomenology and where typical cases are few. 104 medical students of Maharajah's Institute of Medical Sciences, Nellimarla, India volunteered to rate the 3 min 20 sec animation graphics video portraying Ravi as Mania and George as Schizophrenia using Young Mania Rating Scale (YMRS) and Positive and Negative Symptoms of Schizophrenia (PANSS). 53 students of Fifth Semester in two batches of 28 and 25 were compared with 51 students of Eighth Semester on their scoring patterns. All batches had mean YMRS and PANSS scores above cutoff indicating positive diagnosis but those with at least 5 hour theory exposure prior had significantly higher scores on PANSS and YMRS. The major differences in scoring were on Negative symptoms and YMRS. In conclusion, computer generated 3 d graphic virtual patients are quite effective as teaching tools in psychiatry.
\end{abstract}

Keywords: Virtual Patients, Mania, Schizophrenia, Computer graphics Psychiatry, Teaching tool medical, Medical students.

\section{Introduction}

Virtual patients have been used to teach clinical interviewing skills, bioethics, basic patient communication, history taking and clinical decision-making skills for medical students ${ }^{1}$. Berman and colleagues showed that students are satisfied when virtual patients are integrated into the medical curriculum and show an increase in perceived knowledge and skills ${ }^{2}$.

Virtual patients offer many advantages to medical schools and residency programs including: efficiency, standardization, easy accessibility, interactivity, decreased instructor workload, exposure to rare but critical cases, personalized learning, immediate and personalized instruction and feedback, efficacy, improvement of clinical skills in a non-threatening experimental environment, student autonomy, and links to the medical literature ${ }^{34}$.

\section{Review of Literature}

A previous study by the author documents the full details of the use of Computers in Psychiatry ${ }^{5}$.This is the first of its kind study on computer generated virtual patients anywhere in India in the field of Psychiatry.Even across the world very few studies are available on the use of Virtual patients in Psychiatry. These include Mrs. K, a post traumatic stress disorder virtual patient ${ }^{6}$, Denise a bipolar suicidal patient ${ }^{7}$.

Virtual reality and Video games have been used for education and rehabilitation. In Psychiatry, Emil Kraepelin divided functional psychosis into two types- Schizophrenia and Manic depressive illness. Ever since, much of mental hospital psychiatry was devoted to differentiating between Mania and Schizophrenia. In the pre pharmacotherapy era frank psychotic cases with distinct phenomenology were available as clinical material for medical students training in psychiatry. Now a days with wide availability of a variety of drugs across the globe the number of frank cases with classical signs and symptoms have reduced. With programs like National Mental Health program in India these interventions are available in far off rural areas as well making it even more difficult to access untreated full blown psychotic cases. Partially treated cases mask and modify the symptomatology making it difficult to identify true cases. Major thrust of NMHP is to train the trainers and reach the unreached and make Psychiatric care accessible to all by training general physicians, PHC doctors and non psychiatry medical personnel in identifying and providing at least a primary level care. Medical students, budding doctors and MBBS qualified need basic training by posting in Psychiatry hospitals or departments of Psychiatry in Medical colleges which have proved unequal to the task due to shortage of staff, resources and typical patients. Traditional techniques of detailed history and MSE while continuing to be the gold standard for specialist psychiatrists, are difficult skills to impart in short one or two day courses. Hence the rationale for this study.

American Psychiatric Association has tried to provide typical case vignettes in a popular publication as DSM IV TR Casebook ${ }^{8}$. Many of the criteria and case descriptions emphasize heavily on the verbal component derived data either by getting information by talking to the patient or the relatives or recording the sample of speech. This leads to highly variable information flow across variable verbal competencies of both the examiner and the examined. To circumvent this problem highly rigid criteria mostly arbitrary or arrived by consensus 
have been developed which score high on reliability but sacrifice validity. No attempt was made to document visual assessments using visual cues except in passing. There is a need for visual representation of these cases as typical cases in the form of a computer graphic based animations that provide glimpses into the core characteristics of a typical disorder. This study is path breaking in this sense that it tries to argue for a paradigm shift in Psychiatric diagnosis and imparting diagnostic skills. An important purpose of training is to screen cases and identify them with further follow on questioning to confirm the diagnosis.

To create typical cases it is necessary to get into the skin of the character, dramatizing certain elements, get the characterization correct and skilfully generate such computer based animation content. Simulation patients can never achieve psychopathology status ${ }^{9} 10$. Videos have ethical and language issues. With so many languages and dialects especially in India to try to capture on video the precise moment of emerging psychopathology is a foolhardy exercise. Computer animation and graphics have clear cut advantages. The idea is to develop universal norms irrespective of socio economic backgrounds, ethnic or language or regional issues especially in Mania and Schizophrenia which were shown to have more or less similar manifestations and prevalence across the world. Hence these two conditions were chosen for exploring Virtual patients as a teaching tool Fig 1.- George - Schizophrenia lost in his own world, Fig.2. Ravi - Mania smiling with elated mood.

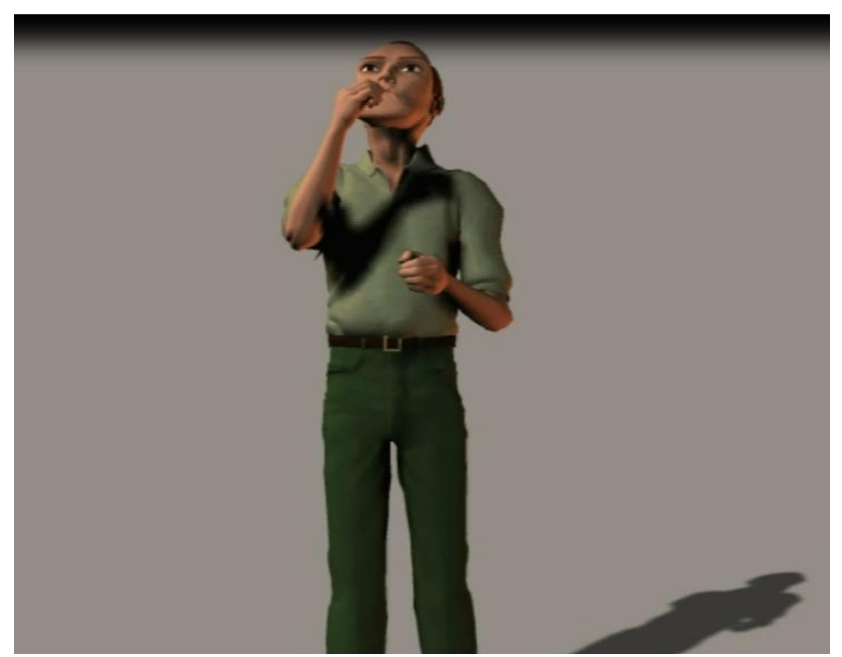

Fig. 1.

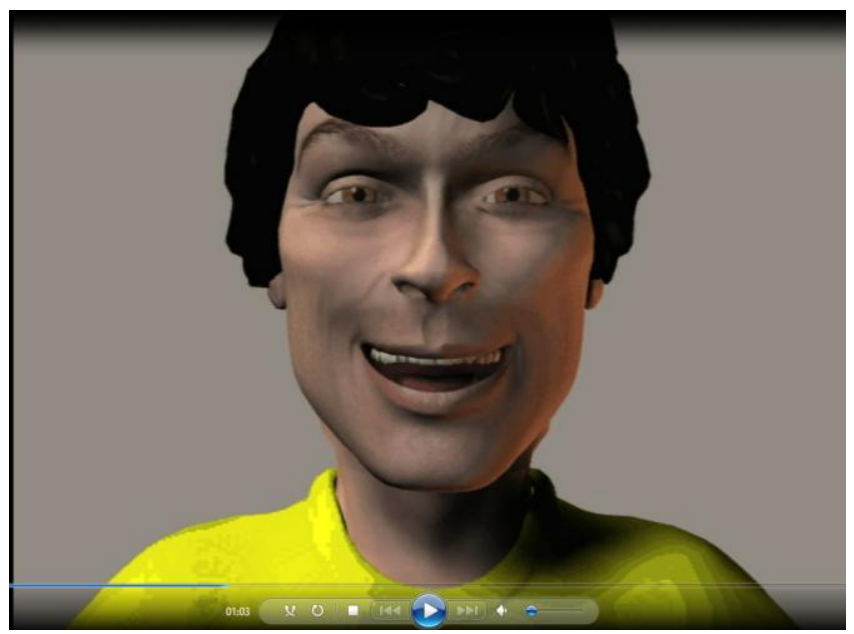

Fig. 2.

The Aims of this study therefore are threefold: 1 . To study the feasibility of using computer graphics based virtual patients as a teaching tool for medical students posted to Psychiatry. 2. To evaluate the duration of exposure to basics of psychiatry theory before exposure to Virtual patients. 3. To assess the predominantly visual models vis a visthe heavily verbalized mode of psychiatric diagnostic procedures by using standardized rating scales used for live patients. 


\section{Materials and Methods}

The animation video of 3 minutes 20seconds duration was designed, created, and implemented by the author at the Maharajah's Institute of Medical Sciences,Nellimarla since 2008 and generally received a standing ovation when shown to every batch of medical students. In this study it was taken up for formal evaluation. The characters of Mania and Schizophrenia were created using Poser. Based on the vast clinical experience of the author for more than two decades of clinical practice in Psychiatry, a profile of a typical Manic and Schizophrenic patient was created. The Manic patient called Ravi was portrayed as a fairly well built young man who was dynamic, hyperactive, elated, confident, brash young man who is shown trying to show his prowess by taming a wild horse to ride but ultimately falling, racing by running against a formula one racing car, a style of walking and sitting oozing grandiosity, wearing bright yellow $\mathrm{T}$ shirt, sporting a smile when taking up the challenges while showing irritability when failing in them. His lack of judgement is shown in scenes like trying to jump over a racing car, fighting with the horse etc. The characterization comprises of hypomania leading on to mania. The Schizophrenia patient is named George and his facial features show an odd, eccentric type of look. He wears a green shirt and mostly shown walking, lying down or sitting on the floor, often lost in his own world. Auditory Hallucinations are portrayed as a number of faces hovering over him while he is writhing on the floor trying to avoid them. To show his imagined interaction with forces that are not natural, skeletons are shown dancing around him while one of them interacts with him by flipping him over to suggest delusions of control and passivity phenomena. Fig. 3 and 4.

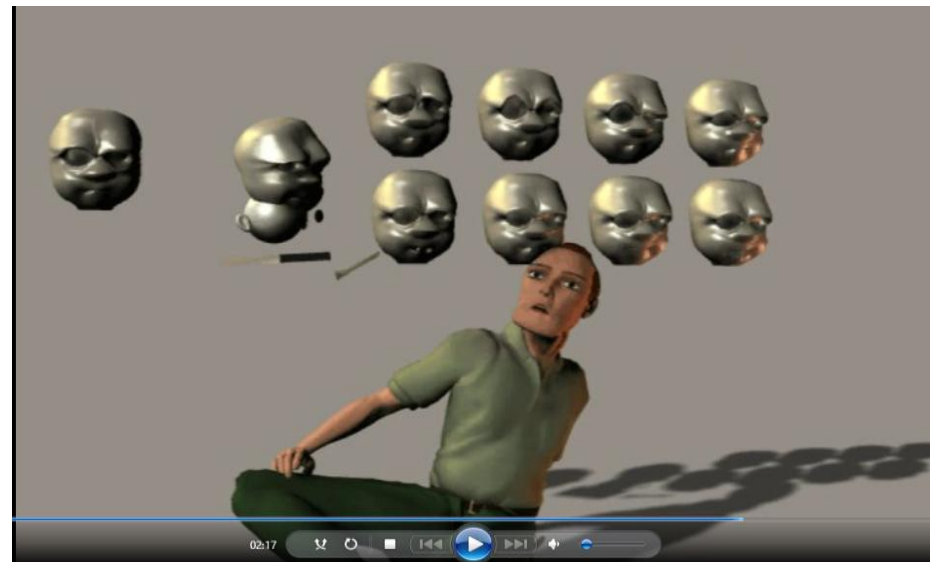

Fig. 3. George - Schizophrenia hearing voices, represented as many faces troubling him.

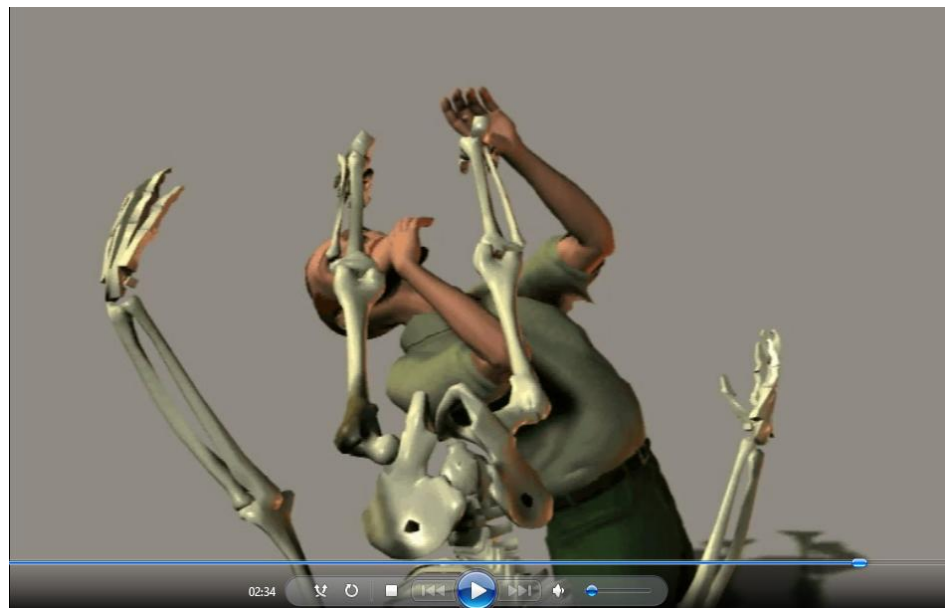

Fig. 4. Delusions of control represented as a skeleton flipping him over.

His final scene shows him walking uncomfortably close to a railway locomotive showing suicidal intent and getting mildly knocked over resulting in an incongruous expression on his face. Compared to the antics of the manic Ravi which evoke mirth and laughter, George mostly evokes a bewildered response from the viewer.

These characters were imported into 3D studio Max and animated, set the background or merged with scenes in the background or with other videos or animations to create scenes. Each scene was again rendered on the available rendering tools of 3D studio max to a DVD quality after adjusting for lighting and other variables 
producing short bits of film in .avi format lasting a few seconds. Depending on the scenes rendering would take hours at times. These avi format videos were then laid out on a video editor, music tracks added, scenes edited, titles added and the whole video created in MPEG 4 format. No speech was used and background music was the only aural input. The final output being an animation video graphic which can be viewed on any computer or DVD player or displayed on a Screen using a multi media projector.

This entire process which took several weeks was done by the author himself after training himself incomputer graphics in order to improve authenticity of characterization of the two disorders.

In this study, of 54 students of $8^{\text {th }}$ semester who were asked to complete scoring on YMRS - Young Mania Rating Scale and PANSS Positive and Negative Symptoms of Schizophrenia 3 were excluded leaving 51 good for the study, due to incomplete forms submitted by 2 by ignoring the items on the backside part of the scoring sheet and 1 due to creating an artistic pattern of responses without actually reading the items!! Similarly of the 30 members of $5^{\text {th }}$ semester batch 1 two were excluded leaving 28 good ratings and of the 30 in $5^{\text {th }}$ semester batch 2 five were excluded leaving 25 for analysis.A total of 104 medical students were thus able to participate in the study.

Initial comparisons were conducted to find out the scoring patterns between each of the 3 groups fifth semester batch 5B1(28 members) who had one week exposure to psychiatry theory and fifth semester batch 5B2 (25 members) who were briefly told about psychiatry and psychosis, delusions, hallucinations etc. without giving details of what is Mania and Schizophrenia and shown the animation video on the very first day of clinical posting. The other group comprised (51 students)of $8^{\text {th }}$ semester students $8 \mathrm{~B}$ who had a weekly theory class for one hour on psychiatry for 6 months including mania and schizophrenia which required 3 hours each to complete. They were shown the video on the projection system in the lecture gallery with full sound in the last class at the end of 6months.5 repeats were shown in the same session to enable scoring. The first two groups were shown the video on a laptop in the clinical demonstration room. Different angles were used for the 5 repeat shows to enable the entire class to see it without glare.

\section{Results}

Results show the ultra brief exposure to psychiatry of one hour on the first day of clinical posting before the video was shown had significantly less psychopathology identified and scored compared to the one week exposure and 6months exposure showing that it's a good idea to introduce adequate theory of the subject before video exposure. The difference between the one week theory group and 6 months theory group of $8^{\text {th }}$ semester who already had exposure to 2 weeks clinical live case exposure in their $5^{\text {th }}$ semester one and a half years previously was not very significant in any of the areas, whether it was PANSS positive symptoms, negative symptoms, general symptoms, or Young Mania rating scale!! However, even a brief introduction of an hour enabled the $5^{\text {th }}$ semester $2^{\text {nd }}$ batch to be able to score above the cut off scores of mania and schizophrenia in PANSS and YMRS. All batches had positive identification of the virtual patients of Mania and Schizophrenia as evaluated by the cutoff scores of PANSS( $\mathrm{P}>18 ; \mathrm{N}>21)$ and YMRS(above 20) as can be seen from Table 1. George schizophrenia was evaluated on PANSS alone while Ravi Mania was evaluated on YMRS only.

\begin{tabular}{|c|c|c|c|c|c|c|c|c|c|}
\hline \multicolumn{10}{|c|}{ TABLE 1} \\
\hline & & \multirow[t]{2}{*}{$\mathrm{N}$} & \multirow[t]{2}{*}{ Mean } & \multirow[t]{2}{*}{$\begin{array}{c}\text { Std. } \\
\text { Deviation }\end{array}$} & \multirow[t]{2}{*}{$\begin{array}{l}\text { Std. } \\
\text { Error }\end{array}$} & \multicolumn{2}{|c|}{$\begin{array}{l}\text { 95\% Confidence Interval for } \\
\text { Mean }\end{array}$} & \multirow[t]{2}{*}{$\begin{array}{l}\text { Minimu } \\
\mathrm{m}\end{array}$} & \multirow[t]{2}{*}{$\begin{array}{l}\text { Maximu } \\
\mathrm{m}\end{array}$} \\
\hline & & & & & & $\begin{array}{l}\text { Lower } \\
\text { Bound }\end{array}$ & Upper Bound & & \\
\hline \multirow[t]{4}{*}{$P$} & $5 \mathrm{~B} 2$ & 25 & 28.00 & 5.598 & 1.120 & 25.69 & 30.31 & 19 & 42 \\
\hline & $5 \mathrm{~B} 1$ & 28 & 30.75 & 6.168 & 1.166 & 28.36 & 33.14 & 12 & 42 \\
\hline & $8 \mathrm{~B}$ & 51 & 28.98 & 7.503 & 1.051 & 26.87 & 31.09 & 14 & 46 \\
\hline & Total & 104 & 29.22 & 6.755 & .662 & 27.91 & 30.53 & 12 & 46 \\
\hline \multirow[t]{4}{*}{$\mathrm{N}$} & $5 \mathrm{~B} 2$ & 25 & 23.80 & 11.864 & 2.373 & 18.90 & 28.70 & 7 & 42 \\
\hline & $5 \mathrm{~B} 1$ & 28 & 30.86 & 7.143 & 1.350 & 28.09 & 33.63 & 16 & 46 \\
\hline & $8 \mathrm{~B}$ & 51 & 28.75 & 7.766 & 1.087 & 26.56 & 30.93 & 7 & 42 \\
\hline & Total & 104 & 28.12 & 9.067 & .889 & 26.36 & 29.89 & 7 & 46 \\
\hline \multirow[t]{4}{*}{ G } & $5 \mathrm{~B} 2$ & 25 & 60.96 & 21.291 & 4.258 & 52.17 & 69.75 & 21 & 96 \\
\hline & $5 \mathrm{~B} 1$ & 28 & 70.21 & 12.072 & 2.281 & 65.53 & 74.90 & 49 & 91 \\
\hline & $8 B$ & 51 & 69.75 & 14.384 & 2.014 & 65.70 & 73.79 & 41 & 98 \\
\hline & Total & 104 & 67.76 & 16.096 & 1.578 & 64.63 & 70.89 & 21 & 98 \\
\hline \multirow[t]{4}{*}{$\mathrm{Y}$} & $5 B 2$ & 25 & 29.36 & 8.366 & 1.673 & 25.91 & 32.81 & 13 & 49 \\
\hline & 5B1 & 28 & 35.21 & 7.838 & 1.481 & 32.18 & 38.25 & 20 & 46 \\
\hline & $8 B$ & 51 & 34.06 & 7.693 & 1.077 & 31.90 & 36.22 & 15 & 50 \\
\hline & Total & 104 & 33.24 & 8.135 & .798 & 31.66 & 34.82 & 13 & 50 \\
\hline
\end{tabular}

panss and ymrs score means for all the three batches $5 \mathrm{~b} 2,5 \mathrm{~b} 1,8 \mathrm{~b}$ : y for 11 items of ymrs ; panss - $\mathrm{p}$ for $\mathrm{p} 1$ to $\mathrm{p} 7$ positive symptoms; $\mathrm{n}$ for $\mathrm{n} 1$ to $\mathrm{n} 7$ negative symptoms; $\mathrm{g}$ for $\mathrm{g} 1$ to $\mathrm{g} 16$ general. 
The means of all the areas of P N G of PANSS and total score of YMRS are way lower in the 5B2 group compared to the other two groups.

One can see ANOVA showing statistical significance of $\mathrm{p}<0.05$ in Negative symptoms, and YMRS and almost there in case of General symptoms $(\mathrm{p}=0.051)$. Positive symptoms were not significantly differently scored amongst the 3 groups $(\mathrm{p}=0.317)$ as shown in Table 2 .

\begin{tabular}{|c|c|c|c|c|c|c|}
\hline \multicolumn{7}{|c|}{ TABLE 2.} \\
\hline & ANOVA & $\begin{array}{l}\text { Sum of } \\
\text { Squares }\end{array}$ & df & Mean Square & $\mathrm{F}$ & Sig. \\
\hline \multirow[t]{3}{*}{$\mathrm{P}$} & Between Groups & 105.683 & 2 & 52.842 & 1.162 & .317 \\
\hline & Within Groups & 4594.230 & 101 & 45.487 & & \\
\hline & Total & 4699.913 & 103 & & & \\
\hline \multirow{3}{*}{$\mathrm{N}$} & Between Groups & 696.260 & 2 & 348.130 & 4.525 & .013 \\
\hline & Within Groups & 7771.115 & 101 & 76.942 & & \\
\hline & Total & 8467.375 & 103 & & & \\
\hline \multirow[t]{3}{*}{ G } & Between Groups & 1525.630 & 2 & 762.815 & 3.062 & .051 \\
\hline & Within Groups & 25159.361 & 101 & 249.103 & & \\
\hline & Total & 26684.990 & 103 & & & \\
\hline \multirow[t]{3}{*}{$\mathrm{Y}$} & Between Groups & 519.693 & 2 & 259.846 & 4.168 & .018 \\
\hline & Within Groups & 6297.298 & 101 & 62.349 & & \\
\hline & Total & 6816.990 & 103 & & & \\
\hline
\end{tabular}

The fifth semester batch 2 (5B2) had highly significant differences on both scales PANSS and YMRS with both groups ie. $8 \mathrm{~B}$ and $5 \mathrm{~B} 1$ when seen on post hoc analysis. This shows up as $p=0.04$ and $p=0.023$ on $5 \mathrm{~B} 2$ comparison with $5 \mathrm{~B} 1$ and $8 \mathrm{~B}$ respectively for Negative symptoms $\mathrm{N} ; \mathrm{p}=0.036$ and $\mathrm{p}=0.025$ for General symptoms $\mathrm{G}$ and $\mathrm{p}=0.08$ and 0.017 for YMRS as can be seen in Table 3.No differences could be seen across positive symptoms rating.

Table 3.

\begin{tabular}{|l|l|l|l|}
\hline $\mathrm{P}$ & $5 \mathrm{~B} 2$ & $5 \mathrm{~B} 1$ & $\mathrm{p}=0.141$ \\
\hline & & $8 \mathrm{~B}$ & $\mathrm{p}=0.553$ \\
\hline $\mathrm{N}$ & $5 \mathrm{~B} 2$ & $5 \mathrm{~B} 1$ & $\mathbf{p}=\mathbf{0 . 0 4}$ \\
\hline & & $8 \mathrm{~B}$ & $\mathbf{p}=\mathbf{0 . 0 2 3}$ \\
\hline $\mathrm{G}$ & $5 \mathrm{~B} 2$ & $5 \mathrm{~B} 1$ & $\mathbf{p}=\mathbf{0 . 0 3 6}$ \\
\hline & & $8 \mathrm{~B}$ & $\mathbf{p}=\mathbf{0 . 0 2 5}$ \\
\hline YMRS & $5 \mathrm{~B} 2$ & $5 \mathrm{~B} 1$ & $\mathbf{p}=\mathbf{0 . 0 8}$ \\
\hline & & $8 \mathrm{~B}$ & $\mathbf{p}=\mathbf{0 . 0 1 7}$ \\
\hline
\end{tabular}

If one takes the YMRS scores for the 51 students $8 \mathrm{~B}$ batch and plots them on a bar chart one can find that certain items could not be scored adequately as it's a visual medium as against the auditory nature of the items to be rated for example flight of ideas, sexual interest etc. which can only be ascertained by talking to a patient. This is so for Sexual interest $\mathrm{Y} 3=0.78$, Sleep $\mathrm{Y} 4=1.75$, Thought disorder $\mathrm{Y} 7=2.37$, Appearance Y10=1.31 items of YMRS as seen in Fig. 5. while on the PANSS its not that clear, apparently the auditory hallucinations could be well represented as faces troubling the patient.

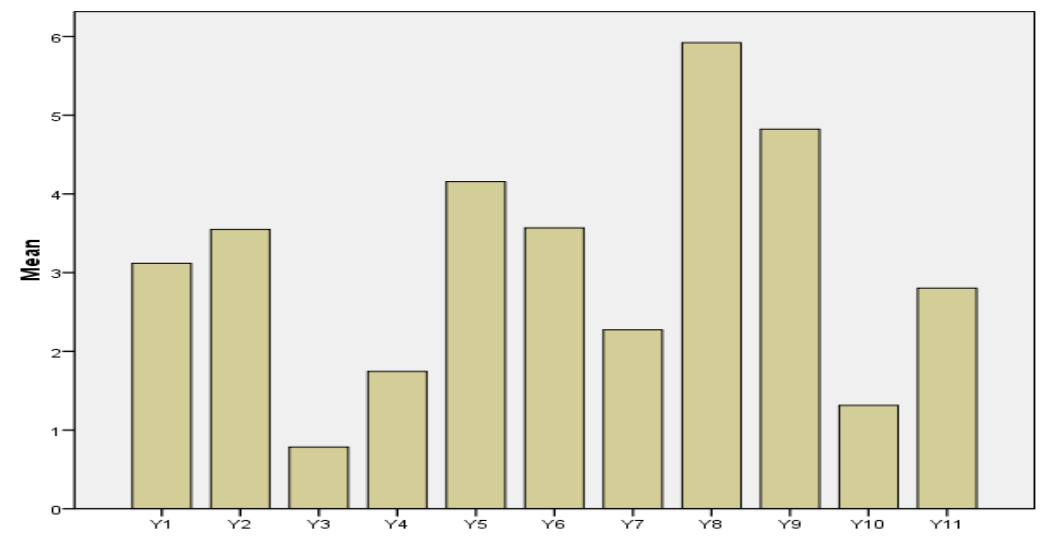

Fig. 5.

Within the groups in ANOVA on the positive symptoms $\mathrm{P} 1$ to 7 and negative symptoms of N1 to N7 on PANSS and YMRSthe difference was highly significant for the entire $5^{\text {th }}$ semester batch of 53 indicating that 
some symptoms rated very heavily against other symptoms. The same results were obtained for 51 students of 8th semester on ANOVA - highly significant on positive, negative symptoms of PANSS and YMRS mania rating scale as can be seen in the tables 4 , and 5 .

\begin{tabular}{|c|c|c|c|c|c|c|}
\hline \multicolumn{7}{|c|}{ TABLE 4} \\
\hline & PANSS & $\begin{array}{l}\text { Sum of } \\
\text { Squares }\end{array}$ & df & Mean Square & $\mathrm{F}$ & Sig. \\
\hline \multirow[t]{3}{*}{$\mathrm{P}$} & Between Groups & $\begin{array}{r}296.491 \\
(263.204)\end{array}$ & 6 & $\begin{array}{r}49.415 \\
(43.867)\end{array}$ & $\begin{array}{r}16.081 \\
(13.028)\end{array}$ & $\begin{array}{r}.000 \\
(0.000)\end{array}$ \\
\hline & Within Groups & $\begin{array}{r}1118.528 \\
(1178.510)\end{array}$ & $\begin{array}{r}364 \\
(350) \\
\end{array}$ & $\begin{array}{r}3.073 \\
(3.367) \\
\end{array}$ & & \\
\hline & Total & $\begin{array}{r}1415.019 \\
(1441.714)\end{array}$ & $\begin{array}{r}370 \\
(356)\end{array}$ & & & \\
\hline \multirow[t]{3}{*}{$\mathrm{N}$} & Between Groups & $\begin{array}{r}108.183 \\
(120.269)\end{array}$ & 6 & $\begin{array}{r}18.031 \\
(20.045)\end{array}$ & $\begin{array}{r}4.529 \\
(5.963)\end{array}$ & $\begin{array}{r}.000 \\
(0.000)\end{array}$ \\
\hline & Within Groups & $\begin{array}{r}1449.132 \\
(1176.471) \\
\end{array}$ & $\begin{array}{r}364 \\
(350) \\
\end{array}$ & $\begin{array}{r}3.981 \\
(3.361) \\
\end{array}$ & & \\
\hline & Total & $\begin{array}{r}1557.315 \\
(1296.739)\end{array}$ & $\begin{array}{r}370 \\
(356)\end{array}$ & & & \\
\hline
\end{tabular}

Figures in brackets ( ) -51 members of $8 \mathrm{~B}$. Rest of the numbers -53 members of $5^{\text {th }}$ semester combined

\begin{tabular}{|c|c|c|c|c|c|}
\hline \multicolumn{6}{|c|}{ TABLE 5} \\
\hline YMRS & Sum of Squares & $\mathrm{df}$ & Mean Square & $F$ & Sig. \\
\hline Between Groups & $\begin{array}{r}935.897 \\
(1205.037)\end{array}$ & 10 & $\begin{array}{r}93.590 \\
(120.504)\end{array}$ & $\begin{array}{r}25.891 \\
(40.320\end{array}$ & $\begin{array}{r}.000 \\
(0.000)\end{array}$ \\
\hline Within Groups & $\begin{array}{r}2067.660 \\
(1643.765)\end{array}$ & 572 & $\begin{array}{r}3.615 \\
(2.989)\end{array}$ & & \\
\hline Total & $\begin{array}{r}3003.557 \\
(2848.802)\end{array}$ & 582 & & & \\
\hline
\end{tabular}

Figures in brackets ()$-51$ members of $8 \mathrm{~B}$. Rest of the numbers - 53 members of 5 th semester combined

From this one can make an indirect inference that much smaller number of components can explain more of the variance in the data and thus the core concepts required to create effective models can even further be whittled down to just a few. This however, requires multivariate analysis including factor analysis techniques like principal component analysis or other statistical ways of analyzing the data like cluster analysis which form the subject of our next paper.

\section{Discussion}

This study was able to demonstrate the efficacy of virtual patients as a source of knowledge for psychiatry naïve trainee medical students. It was however found more useful if additional short term theoretical training of about 5 hours were included before presenting the animation video material based on the fact that the first batch of $5^{\text {th }}$ Semester (batch of 28) were taught basics of psychiatry for 5 days in the one week preceding for one hour each day.

This study was also able to confirm the possibility of creating tools which are in the visual domain as opposed to a primarily verbal domain that the history of psychiatry has been steeped in(Fig 6,7). Psychiatric interview, psychiatric case records, talking therapies, diagnostic criteria, psychiatry books and literature all focus heavily on verbal skills and verbal report.Thus, this represents a significant paradigm shift in the way in which psychiatrists can approach patients and analyze the symptomatology. Hopefully, world bodies like American Psychiatric Association and World Psychiatric Association would consider the option of developing training manuals which include videos of virtual patients as tools that would illustrate the particular disorders since evidence is growing about its utility ${ }^{11} 12$.

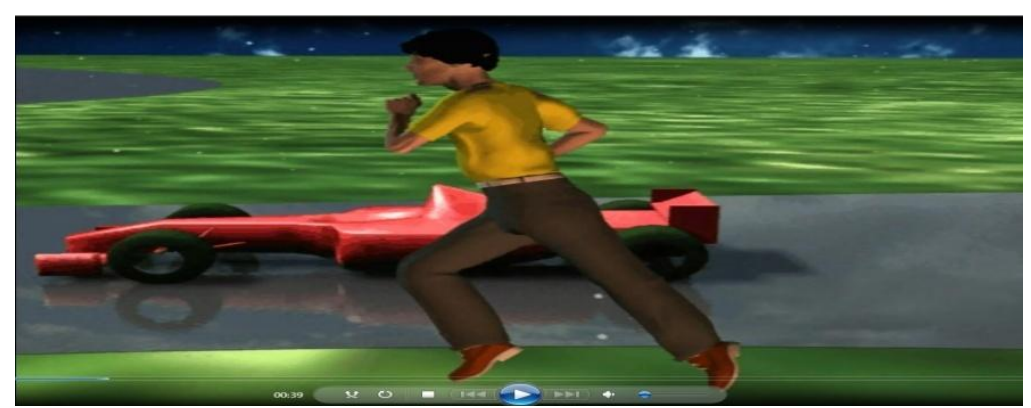


Fig. 6. Ravi Mania trying to outrun a racing car - A screenshot of the Animation graphic video

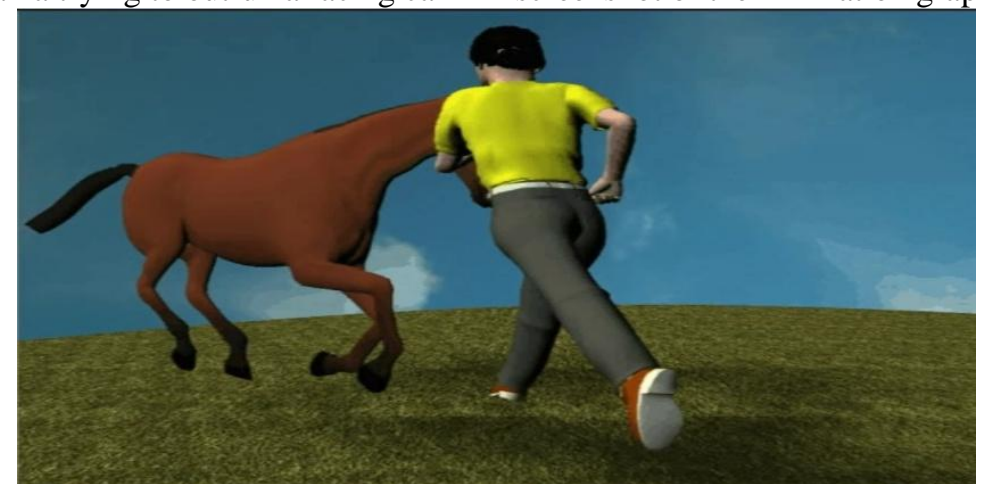

Fig. 7. Ravi Mania in vivid realistic Computer generated 3 D Graphics trying to mount a horse.

This study could also confirm the feasibility of using traditional conservative rating scales on virtual patients as if they were live patients. Students were quite comfortable using YMRS and PANSS ${ }^{13}{ }^{14}$. Psychiatric education which depends a great deal on didactic lectures, case taking, case presentation and discussion, can now add another methodology to its armamentarium. It is clear that these new tools like virtual patients are not meant to supplant traditional teaching but to supplement it. The limitations of this study are that the findings reflect a single point of time rating rather than a pre and post video rating to assess incremental change in knowledge and skills. Making it interactive would certainly have helped proper learning and revision, clarification etc. The advantages of Virtual patients in psychiatry would be to recreate emergency situations like suicide, aggression, violence, self harm and psychotic phenomena which are quite challenging to expose the novice trainee to.

However, much more work needs to be done to be able to make specific guidelines ${ }^{15} 16$ as to which core symptoms best represent the disorder but such a scenario would certainly prove to be rewarding for future research.

\section{Conclusion}

Computer generated 3 D Graphics animation videos of Virtual Patients are an exciting new paradigm that offer scope as a teaching tool for medical students and also have the potential of changing and challenging the thought process of Psychiatric diagnosis from a predominantly verbal medium to one that encompasses the visual as well. It is particularly advantageous in studying violent, aggressive, suicidal patients.

\section{References}

[1]. Triola M, Feldman H, Kalet AL, Zabar S, Kachur EK, Gillespie C, Anderson M, Griesser C, Lipkin M. A randomized trial of teaching clinical skills using virtual and live standardized patients. J Gen Intern Med 2006;21:424-9.

[2]. Berman N, Fall LH, Smith S, Levine DA, Maloney CG, Potts M, Siegel B, Foster-Johnson L. Integration strategies for using virtual patients in clinical clerkships. Acad Med 2009; 84:942-9.

[3]. Huang G, Reynolds R, Candler C. Virtual patient simulation at US and Canadian medical schools. Acad Med 2007; 82:446-51.

[4]. Ellaway R, Poulton T, Fors U, McGee JB, Albright S. Building a virtual patient commons. Med Teacher 2008; 30:170-4.

[5]. Radhakanth C. Computers in Psychiatry: Development of a database and its analysis in Schizophrenia. Dissertation submitted to University of Health Sciences, Andhra Pradesh 1990.

[6]. Pantziaras I, Fors U, Ekblad S (2015) Innovative Training with Virtual Patients in Transcultural Psychiatry: The Impact on Resident Psychiatrists' Confidence. PLoS ONE 10(3): e0119754.

[7]. Foster A, Robb A, Cordar A, Chaudhary N, Noseworthy D, Lok B, Denise: A Virtual Patient. MedEdPORTAL Publications, 2015, $11,10145$.

[8]. Spitzer RL [Ed.] DSM-IV-TR Casebook. A Learning Companion to the Diagnostic and Statistical Manual of Mental Disorders, Fourth Edition, Text Revision, American Psychiatric Publishing, 2002.

[9]. Wilkening, G.L., Gannon, J.M., Ross, C. et al. Utility of Branched Narrative Virtual Patient. Acad Psychiatry, 2016,. doi:10.1007/s40596-016-0531-148

[10]. Pataki, C., Pato, M., Sugar, J., Rizzo, A., St-George, C., Kenny, P., \& Parsons, T.D. Virtual Patients as a Novel Teaching Tool in Psychiatry. Academic Psychiatry, 2012, 36, 398-400.

[11]. Cendan J, Lok B, The Use of Virtual Patients in Medical School Curricula. AdvPhysiol Educ. 2012 Mar; 36(1): 48-53. doi: 10.1152/advan.00054.2011

[12]. Bearman M. Is virtual the same as real? Medical students' experiences of a virtual patient. Acad Med, 2003, 78: 538- 545.

[13]. Young RC, Biggs JT, Ziegler VE, Meyer DA. "A rating scale for mania: reliability, validity and sensitivity". Br J Psychiatry. 1978, 133 (5): 429-35. doi:10.1192/bjp.133.5.429

[14]. Kay SR, Fiszbein A, Opler LA (1987). "The positive and negative syndrome scale (PANSS) for schizophrenia." (PDF). Schizophr Bull. 1987, 13 (2): 261-76. doi:10.1093/schbul/13.2.261

[15]. Kleinert R et al, Web-Based Immersive Virtual Patient Simulators: Positive Effect on Clinical Reasoning in Medical Education, J Med Internet Res 2015;17(11):e263, doi:10.2196/jmir.5035

[16]. James Bateman, Maggie Allen,DiptiSamani, Jane Kidd, David Davies, Virtual patient design: exploring what works and why. A grounded theory study. Medical Education 2013: 47: 595-606 doi: 10.1111/medu.12151 